\title{
Integration of distributed generation and compensating capacitor in radial distribution system via firefly algorithm
}

\author{
N. Khuan, S. R. A. Rahim, M. H. Hussain, A. Azmi1, S. A. Azmi \\ School of Electrical System Engineering, Universiti Malaysia Perlis (UniMAP), Malaysia
}

\begin{tabular}{|c|c|}
\hline Article Info & ABSTRACT \\
\hline Article history: & This paper presents an integration of distributed generation and capacitor in \\
\hline Received Jan 18, 2019 & radial distribution system via Firefly Algorithm (FA). In this study, the FA is \\
\hline Revised Apr 22, 2019 & compensation schemes namely distributed generation (DG) and \\
\hline Accepted May 13, 2019 & $\begin{array}{l}\text { compensating capacitor (CC). The FA which is a meta-heuristic algorithm is } \\
\text { inspired by the flashing behavior of fireflies. The proposed technique was }\end{array}$ \\
\hline Keywords: & $\begin{array}{l}\text { tested on IEEE Reliability Test systems namely the IEEE } 69 \text {-bus and the } \\
\text { program was developed using the MATLAB programming software. }\end{array}$ \\
\hline $\begin{array}{l}\text { Compensating capacitor } \\
\text { Distributed generation }\end{array}$ & $\begin{array}{l}\text { The results shown a significant reduction in the line losses and voltage } \\
\text { profile improvement has been obtained with the installation of distributed } \\
\text { generation and capacitor in the system. }\end{array}$ \\
\hline
\end{tabular}

Copyright (C) 2019 Institute of Advanced Engineering and Science. All rights reserved.

\section{Corresponding Author:}

Siti Rafidah Abdul Rahim,

School of Electrical System Engineering,

Universiti Malaysia Perlis (UniMAP),

02600, Arau, Perlis, Malaysia.

Email: rafidah@unimap.edu.my

\section{INTRODUCTION}

For several years, a variety of techniques and procedures had been developed by many researchers for loss minimization issue and allocation of DG. This problem is a long progressing issue mainly in distribution system. However its effect led to temperature rise due to significant voltage drop through the distribution line. Thus, compensation scheme should be proper scheduled in the attempt to alleviate the voltage drop phenomenon. Voltage drop problem may cause insecure power delivery to consumer. The consequence of voltage drop is loss increment in the whole system. Thus it requires compensating scheme such as static Var compensation (SVC) [1], compensating capacitor [2] and DG [3-5]. In the present power system, DG installation has shown an escalating growth in the distribution networks around the world due to the raise in promotion towards utilization of renewable energy resources and development of cogeneration plants. Distributed generations (DGs) is also known as embedded energy refers to power generation at the point of consumption. In other words, DGs is the process of generating electricity at a specific location and then connecting that supply into the electricity network. While capacitor bank is widely used in AC power supply for error correction. Generally, inductive load causes susceptible to phase shifts and power factor lags in the power supply cause a loss of system efficiency if left uncorrected. With proper planning, the integration of distributed generation and capacitor in a distribution system would lead to enhancement in the network performance in terms of the voltage profile improvement reduction in line losses and improve reliability and quality [6-9]. As the result, the total demand required from the grid could be reduced, thus cutting the need to strengthen the feeders connecting the network to the grid.

Thus, the best location and sizing factors are importance issues in the implementation of distributed generation and capacitor bank in the distribution system[10]. With optimal placement and sizing of distribution and sizing of distributed generation or compensating capacitor or both of them, the maximum 
possible advantages could be obtained especially to improve the performance and to reduce losses in the system $[4,11-14]$.

A lot of conventional analytical methods such as loss sensitivity method, Linear Programming (LP) [15-17] and Lagrangian approach [18, 19] have been applied to solve the allocation problem. Nevertheless, these methods are very time-consuming and low reliable, especially when dealing with complex power problems [20-22]. With the increase of computation intelligence technologies especially in Nature Inspired Algorithm (NIA), many researchers have turned their attention to meta-heuristic approach [23]. The integration of DG and CC units provides potential benefits to the conventional distribution systems.

In this study, the new swarm intelligence approach that utilizes FA to determine the best location and sizing of DG, CC and both DG-CC in order to minimize the total system real power loss is proposed. By using FA, the size and location of proposed schemes can be determined simultaneously. This paper presents an integration of DG and CC in radial distribution system via Firefly Algorithm (FA) and the effectiveness of the proposed methodology was verified by the analysis on a 69-bus distribution system.

\section{RESEARCH METHOD}

The Firefly Algorithm (FA) is a metaheuristic nature-inspired optimization algorithm which it is invented by Yang for solving the multimodal optimization problem [24-26]. It creates based ib the behavior of fireflies, or lightning bugs. Fireflies have about more than two thousand species where the flashes often unique for each particular species. The flashing light is produced by a process of bioluminescence where it is functioning as signaling system.

Generally, the flashes from firefly are to attract mating partners and to attract potential prey. Firefly algorithm has three particular ideal rules which are based on the behavior of firefly. These are following :

a) All fireflies are unisexual so that any individual firefly will be attracted to all other fireflies;

b) Attractiveness is proportional to their brightness, and for any two fireflies, the less bright one will be attracted by (and thus move towards) the brighter one; however, the intensity (apparent brightness) decrease as their mutual distance increases;

c) If there are no fireflies brighter than a given firefly, it will move randomly.

\subsection{FA for Optimal Allocation and Sizing}

In this section, FA is proposed to find the optimal location and size of compensating schemes in the distribution system to minimize the total loss in the system. By minimizing the loss, the voltage profile at each bus is also expected to be improved. The variables of the optimal allocation of schemes are coded as follows:

$$
x=\left[x_{1 L}, x_{1 S}, \ldots . x_{n L}, x_{n S}\right]
$$

where $\mathrm{L}$ indicates the location of compensating scheme, $\mathrm{S}$ indicates the size of compensating scheme and $\mathrm{n}$ is the number of compensating scheme that need to be installed in the system. These variables then are included in the data of load flow and the load flow is executed to obtain the total loss of the system.

The procedure to obtain the optimal allocation of schemes requires load flow to be run iteratively. After obtaining the best location and size of schemes simultaneously, the procedure is stopped. Results will be recorded. The objective function, $\mathrm{f}(\mathrm{x})$ is the results of the total loss of the system, $\mathrm{P}_{\text {Loss }}$ to be minimized, as follows:

$$
f(x)=\min \left(\sum_{j=1}^{\text {line }} \text { Ploss }\right)
$$

Where line is number of transmission lines in the distribution system.

The following procedures were implemented in the simulation in order to determine the optimal sizing of compensating scheme:

Step 1: Generate control variable

Initialization process was conducted by generating control variable using a uniformly distributed random number generation, $X_{i}$. The random numbers represent the value of $x_{i}$ and $\eta_{i}$ as the variable to be optimized. During initialization, the population size depends on the number of individuals.

Step 2: Constraint violation test.

Test the value of $X_{i}$. The calculation of the fitness value $\left(y_{i}\right)$ of each individual is done to ensure the fitness is within the acceptable limit.

Step 3: Selection process for ' $n$ ' fireflies

Based on the ranking data, the best ' $n$ ' population is selected as initial location of ' $n$ ' numbers of fireflies. 
Step 4: Calculate distance and attractiveness

Move firefly $\mathrm{i}$ towards $\mathrm{j}$ in $\mathrm{d}$-dimension. Attractiveness varies with distance $\mathrm{r}$ via exp ${ }^{[-\gamma \mathrm{r}]}$. Evaluate new solutions and update light intensity. The firefly attractiveness, $\beta$ can be defined by (3). The distance between any two fireflies $i$ and $j$ are calculated using the Cartesian distance in Error! Reference source not found.. The movement of firefly $i$ is attracted to another more attractive (brighter) firefly $j$, determined by Error! Reference source not found.

$$
\begin{aligned}
& \beta=\beta_{0} \mathrm{e}^{-\gamma \mathrm{r}^{2}} \\
& r_{i j}=\left\|x_{i}-x_{j}\right\|=\sqrt{\sum_{k=1}^{d}\left(x_{i, k}-x_{j, k}\right)^{2}} \\
& x_{i}=x_{i}+\beta_{0} e^{-\gamma r^{2}}\left(x_{j}-x_{i}\right)+\alpha(\text { rand }-0.5)
\end{aligned}
$$

Step 5: Fitness calculation

Fitness calculation is conducted for all individuals in the population. Fitness value is the one which will undergo the optimization process. The fitness will be maximized or minimized depending on the objective function. Figure 1.

The process of incorporating the FA into optimal allocation of compensating schemes is shown in

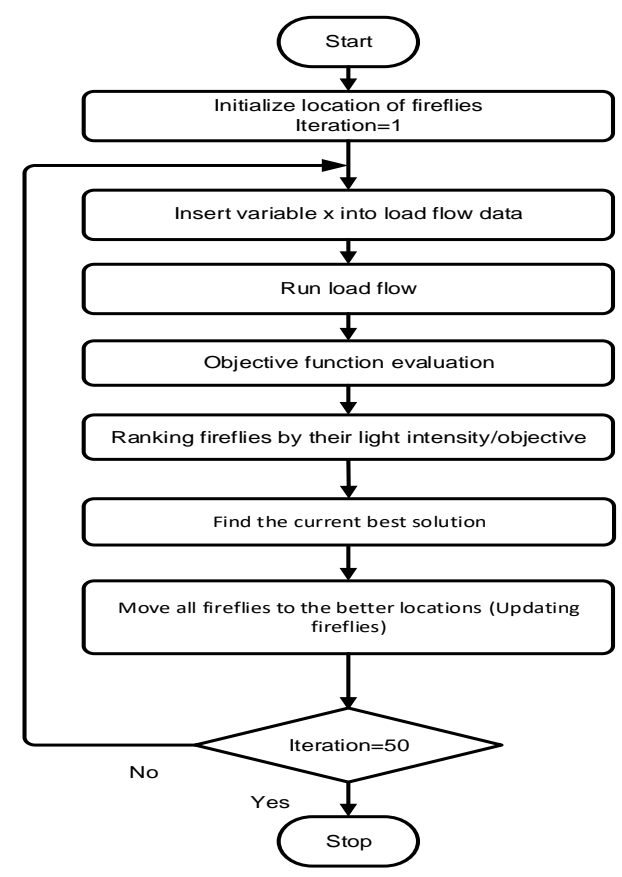

Figure 1. Flowchart for FA algorithm

\section{RESULTS AND DISCUSSION}

The FA has been tested on IEEE 69-bus radial distribution system. Figure 2 shows the single line diagram for the test system with a total real and reactive power demand of $3802.19 \mathrm{~kW}$ and 2694.60 kVAr respectively. The FA properties in this simulation are set as follow:

Number of fireflies: 20

Maximum iteration: 30

Number of DG unit: 1
Schemes size: $0.01 \mathrm{MW}<\mathrm{P}_{\text {schemes }}<2.5 \mathrm{MW}$

Alpha (scaling parameter): 0.25

Minimum value of beta (attractiveness): 0.2 


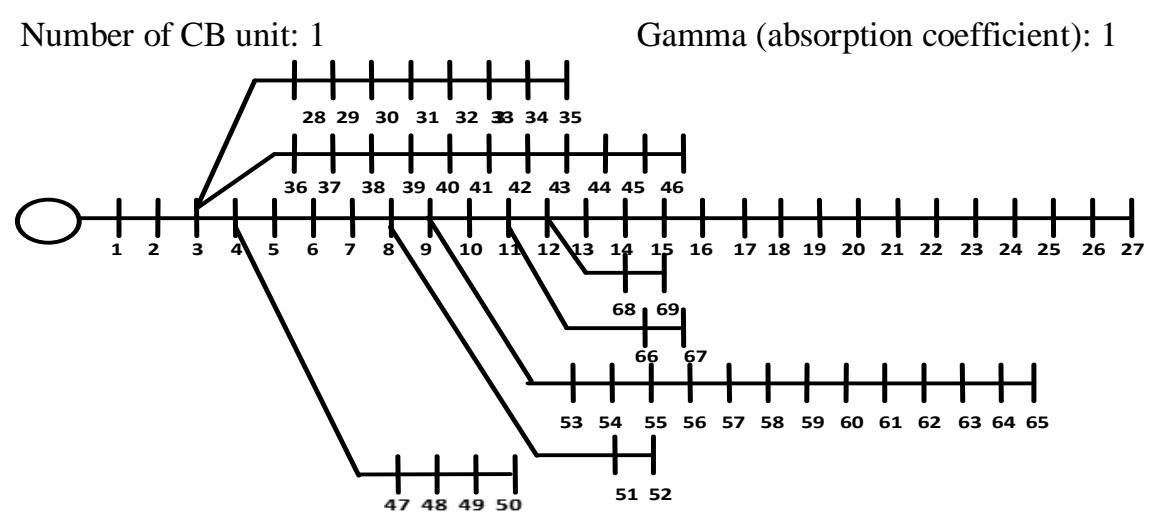

Figure 2. IEEE 69-bus radial distribution system [27]

The aim of this study is to see the impact of the proposed method on the IEEE 69 bus distribution system using different compensating sc. The following tables will show the result after carrying out the FA with random bus selection for 30 samples. Table 1 shows the results of objective function in (2) with the installation of single DG in the system. The minimum loss of $0.0232 \mathrm{MW}$ is experienced by the system when DG is installed at bus 61 with the loss reduction is recorded as $89.7 \%$ as highlighted in yellow.

Table 1. Optimization with Single DG Placement

\begin{tabular}{|c|c|c|c|c|c|}
\hline \multirow{2}{*}{ No. } & \multirow{2}{*}{ Status } & \multicolumn{2}{|c|}{ DG } & \multirow{2}{*}{$\begin{array}{c}\text { Total Losses } \\
\text { MW }\end{array}$} & \multirow{2}{*}{$\begin{array}{c}\text { Loss Reduction } \\
(\%)\end{array}$} \\
\hline & & Location & Sizing (MW) & & \\
\hline 1 & Decrease & 65 & 1.3955 & 0.0617 & 72.56 \\
\hline 2 & Decrease & 11 & 1.8082 & 0.1627 & 27.64 \\
\hline 3 & Decrease & 15 & 0.8848 & 0.1823 & 18.95 \\
\hline 4 & Increase & 34 & 0.0364 & 0.2249 & - \\
\hline 5 & Decrease & 24 & 0.7103 & 0.1882 & 16.33 \\
\hline 6 & Decrease & 2 & 2.5 & 0.2249 & 0.01 \\
\hline 7 & Decrease & 59 & 1.9118 & 0.0435 & 80.65 \\
\hline 8 & Decrease & 2 & 2.5 & 0.2249 & 0.01 \\
\hline 9 & Decrease & 15 & 0.8848 & 0.1823 & 18.95 \\
\hline 10 & Decrease & 24 & 0.7103 & 0.1882 & 16.33 \\
\hline 11 & Decrease & 20 & 0.7837 & 0.1851 & 17.71 \\
\hline 12 & Decrease & 64 & 1.6076 & 0.0408 & 81.87 \\
\hline 13 & Decrease & 20 & 0.7837 & 0.1851 & 17.71 \\
\hline 14 & Increase & 37 & 0.2146 & 0.2249 & - \\
\hline 15 & Decrease & 64 & 1.6076 & 0.0408 & 81.87 \\
\hline 16 & Decrease & 46 & 0.0976 & 0.2248 & 0.03 \\
\hline 17 & Decrease & 53 & 2.5 & 0.1429 & 36.46 \\
\hline 18 & Decrease & 41 & 0.1614 & 0.2249 & 0.01 \\
\hline 19 & Decrease & 14 & 1.0038 & 0.18 & 19.98 \\
\hline 20 & Decrease & 59 & 1.9118 & 0.0435 & 80.65 \\
\hline 21 & Decrease & 40 & 0.1645 & 0.2249 & 0.00 \\
\hline 22 & Decrease & 48 & 0.9295 & 0.2242 & 0.32 \\
\hline 23 & Decrease & 53 & 2.5 & 0.1429 & 36.46 \\
\hline 24 & Decrease & 61 & 1.8368 & 0.0232 & 89.70 \\
\hline 25 & Increase & 31 & 0.0595 & 0.2249 & - \\
\hline 26 & Increase & 35 & 0.0275 & 0.2249 & - \\
\hline 27 & Decrease & 52 & 1.9695 & 0.174 & 22.63 \\
\hline 28 & Increase & 32 & 0.0526 & 0.2249 & - \\
\hline 29 & Decrease & 40 & 0.1645 & 0.2249 & 0.00 \\
\hline 30 & Increase & 34 & 0.0364 & 0.2249 & - \\
\hline
\end{tabular}

Similar study was performed for the integration of single capacitor placement as compensating scheme. The minimum total loss occurs when DG is installed at bus 61 with the system loss of $0.152 \mathrm{MW}$. The optimal capacitor size is 1.33MVar to achieve this result as tabulated in Table 2.

Lastly, the determination of DG location for the installation of DG and capacitor simultaneously is also conducted. The results is tabulated in Table 3. The minimum loss of $0.0235 \mathrm{MW}$ is experienced by the 
system when DG is installed at bus 63 while capacitor at bus 24. This required a DG size of $0.0364 \mathrm{MW}$ and a size of compensating capacitor is $0.3770 \mathrm{MV}$ ar to compensate the system for loss reduction.

Table 2. Optimization with Single Capacitor Placement

\begin{tabular}{|c|c|c|c|c|c|}
\hline \multirow{2}{*}{ No. } & \multirow{2}{*}{ Status } & \multicolumn{2}{|c|}{ Capacitor } & \multirow{2}{*}{$\begin{array}{l}\text { Total Losses } \\
\text { (MW) }\end{array}$} & \multirow{2}{*}{$\begin{array}{c}\text { Loss Reduction } \\
(\%)\end{array}$} \\
\hline & & Location & Sizing (MVAR) & & \\
\hline 1 & Decrease & 62 & 1.3087 & 0.1529 & 32.00 \\
\hline 2 & Increase & 33 & 0.0307 & 0.2249 & - \\
\hline 3 & Decrease & 27 & 0.3976 & 0.215 & 4.42 \\
\hline 4 & Decrease & 18 & 0.5432 & 0.2119 & 5.77 \\
\hline 5 & Increase & 32 & 0.0332 & 0.2249 & - \\
\hline 6 & Decrease & 10 & 1.3283 & 0.2045 & 9.06 \\
\hline 7 & Decrease & 56 & 1.6687 & 0.1898 & 15.60 \\
\hline 8 & Decrease & 57 & 1.4536 & 0.1729 & 23.12 \\
\hline 9 & Increase & 40 & 0.114 & 0.2249 & - \\
\hline 10 & Decrease & 56 & 1.6687 & 0.1898 & 15.60 \\
\hline 11 & Decrease & 61 & 1.33 & 0.152 & 32.41 \\
\hline 12 & Increase & 30 & 0.0379 & 0.2249 & - \\
\hline 13 & Decrease & 10 & 1.3284 & 0.2045 & 9.06 \\
\hline 14 & Decrease & 17 & 0.5435 & 0.2119 & 5.78 \\
\hline 15 & Increase & 38 & 0.1182 & 0.2249 & - \\
\hline 16 & Decrease & 62 & 1.3087 & 0.1529 & 32.00 \\
\hline 17 & Decrease & 8 & 2.0722 & 0.2006 & 10.79 \\
\hline 18 & Increase & 41 & 0.0704 & 0.2249 & - \\
\hline 19 & Increase & 39 & 0.1143 & 0.2249 & - \\
\hline 20 & Decrease & 60 & 1.359 & 0.157 & 30.18 \\
\hline 21 & Decrease & 62 & 1.3087 & 0.1529 & 32.00 \\
\hline 22 & Decrease & 64 & 1.1482 & 0.16 & 28.85 \\
\hline 23 & Increase & 37 & 0.1579 & 0.2249 & - \\
\hline 24 & Decrease & 20 & 0.5094 & 0.2125 & 5.53 \\
\hline 25 & Decrease & 12 & 1.008 & 0.2069 & 8.02 \\
\hline 26 & Decrease & 55 & 1.7434 & 0.1927 & 14.30 \\
\hline 27 & Decrease & 20 & 0.5094 & 0.2125 & 5.53 \\
\hline 28 & Decrease & 6 & 2.1158 & 0.2137 & 4.97 \\
\hline 29 & Decrease & 19 & 0.522 & 0.2123 & 5.62 \\
\hline 30 & Increase & 31 & 0.0366 & 0.2249 & - \\
\hline
\end{tabular}

Table 3. Optimization with DG and Capacitor Placement

\begin{tabular}{|c|c|c|c|c|c|c|c|}
\hline \multirow{2}{*}{ No. } & \multirow{2}{*}{ Status } & \multicolumn{2}{|c|}{$\mathrm{DG}$} & \multicolumn{2}{|c|}{ Capacitor } & \multirow{2}{*}{$\begin{array}{l}\text { Total Losses } \\
\text { (MW) }\end{array}$} & \multirow{2}{*}{$\begin{array}{c}\text { Loss Reduction } \\
(\%)\end{array}$} \\
\hline & & Location & Sizing (MW) & Location & Sizing (MVar) & & \\
\hline 1 & Decrease & 21 & 1.3955 & 34 & 0.7609 & 0.1979 & 12.00 \\
\hline 2 & Decrease & 54 & 1.8082 & 41 & 0.2161 & 0.1362 & 39.45 \\
\hline 3 & Decrease & 66 & 0.8848 & 69 & 0.2660 & 0.1671 & 25.6 \\
\hline 4 & Decrease & 63 & 0.0364 & 24 & 0.3770 & 0.0235 & 89.55 \\
\hline 5 & Decrease & 40 & 0.7103 & 22 & 0.4650 & 0.2141 & 4.82 \\
\hline 6 & Decrease & 52 & 2.5 & 66 & 0.7798 & 0.1679 & 25.33 \\
\hline 7 & Decrease & 19 & 1.9118 & 54 & 1.4475 & 0.1649 & 26.70 \\
\hline 8 & Decrease & 9 & 2.5 & 49 & 1.0083 & 0.1493 & 33.61 \\
\hline 9 & Decrease & 5 & 0.8848 & 39 & 0.0534 & 0.2222 & 1.18 \\
\hline 10 & Decrease & 2 & 0.7103 & 50 & 0.5279 & 0.2241 & 0.37 \\
\hline 11 & Decrease & 17 & 0.7837 & 44 & 0.1611 & 0.1834 & 18.47 \\
\hline 12 & Decrease & 52 & 1.6076 & 47 & 0.8475 & 0.1740 & 22.65 \\
\hline 13 & Decrease & 39 & 0.7837 & 35 & 0.0014 & 0.2256 & 0.33 \\
\hline 14 & Decrease & 4 & 0.2146 & 52 & 1.3795 & 0.2085 & 7.31 \\
\hline 15 & Decrease & 3 & 1.6076 & 42 & 0.1230 & 0.2248 & 0.03 \\
\hline 16 & Decrease & 65 & 0.0976 & 50 & 0.7580 & 0.0611 & 72.84 \\
\hline 17 & Decrease & 40 & 2.5 & 8 & 1.9330 & 0.2007 & 10.75 \\
\hline 18 & Decrease & 4 & 0.1614 & 42 & 0.0628 & 0.2247 & 0.11 \\
\hline 19 & Decrease & 4 & 1.0038 & 19 & 0.5211 & 0.2120 & 5.75 \\
\hline 20 & Decrease & 24 & 1.9118 & 6 & 1.5947 & 0.1814 & 19.34 \\
\hline 21 & Decrease & 8 & 0.1645 & 21 & 0.2892 & 0.1498 & 33.41 \\
\hline 22 & Decrease & 37 & 0.9295 & 56 & 1.6686 & 0.1898 & 15.61 \\
\hline 23 & Decrease & 29 & 2.5 & 41 & 0.0900 & 0.2251 & 0.11 \\
\hline 24 & Decrease & 51 & 1.8368 & 41 & 0.7308 & 0.1630 & 27.54 \\
\hline 25 & Decrease & 62 & 0.0595 & 40 & 0.5212 & 0.0253 & 88.74 \\
\hline 26 & Decrease & 51 & 0.0275 & 28 & 0.5070 & 0.1575 & 29.98 \\
\hline 27 & Decrease & 58 & 1.9695 & 64 & 0.9180 & 0.0450 & 80.01 \\
\hline 28 & Decrease & 21 & 0.0526 & 47 & 1.1209 & 0.1860 & 17.31 \\
\hline 29 & Increase & 44 & 0.1645 & 34 & 0.0239 & 0.2248 & - \\
\hline 30 & Decrease & 67 & 0.0364 & 64 & 1.0300 & 0.1183 & 47.42 \\
\hline
\end{tabular}


A comparative study was done in order to show the capability of the technique to perform DG planning and to ensure the proper placement and sizing of DG unit. The results show the percentage of reduction for installation of DG managed to outperform the other with considerable percentages of loss reduction of $89.70 \%$.

\section{CONCLUSION}

This paper has presented the integration of DG and CC in Radial Distribution System via Firefly Algorithm has been successfully implemented and tested on IEEE 69-Bus Distribution System. The effectiveness of FA was demonstrated and tested. The results indicated that the proper planning of the integration of distributed generation and compensating capacitor in a distribution system would lead to enhancement in the network performance in terms of the loss reduction in the system. The result obtained from this study could be beneficial to the power system operator or to the utilities to identify the compensating scheme placement with a few selection locations to install the DG in the system.

\section{ACKNOWLEDGEMENTS}

The authors would like to acknowledge School of Electrical System Engineering, Universiti Malaysia Perlis for the financial support of this research. This research is supported by Ministry of Education Malaysia under the Fundamental Research Grant Scheme (FRGS) with project code: (Ref Code: FRGS/1/2016/TK04/UNIMAP/02/9).

\section{REFERENCES}

[1] A. Savić and Ž. Durišić, "Optimal sizing and location of SVC devices for improvement of voltage profile in distribution network with dispersed photovoltaic and wind power plants," Appl. Energy, vol. 134, pp. 114-124, 2014.

[2] N. Kanwar, N. Gupta, K. R. Niazi, and A. Swarnkar, "Improved meta-heuristic techniques for simultaneous capacitor and DG allocation in radial distribution networks," Int. J. Electr. Power Energy Syst., vol. 73, pp. 653-664, 2015.

[3] L. Y. Wong, M. H. Sulaiman, S. R. A. Rahim, and O. Aliman, "Optimal distributed generation placement using hybrid genetic-particle swarm optimization,” Int. Rev. Electr. Eng., vol. 6, no. 3, pp. 1390-1397, 2011.

[4] V. V. S. N. Murty and A. Kumar, "Optimal placement of DG in radial distribution systems based on new voltage stability index under load growth," Int. J. Electr. Power Energy Syst., vol. 69, pp. 246-256, 2015.

[5] K. Cabana, J. Candelo, R. Castillo, and E. D. la H. Franco, "Voltage sensitivity analysis to determine the optimal integration of distributed generation in distribution systems," Int. J. Electr. Comput. Eng., vol. 9, no. 1, pp. 55-65, 2019.

[6] M. H. Sulaiman, M. W. Mustafa, A. Azmi, O. Aliman, and S. R. Abdul Rahim, "Optimal allocation and sizing of Distributed Generation in distribution system via Firefly Algorithm," in IEEE International Power Engineering and Optimization Conference, 2012, pp. 84-89.

[7] A. S. Bouhouras, K. I. Sgouras, P. A. Gkaidatzis, and D. P. Labridis, "Optimal active and reactive nodal power requirements towards loss minimization under reverse power flow constraint defining DG type," Int. J. Electr. Power Energy Syst., vol. 78, pp. 445-454, 2016.

[8] I. Rahman and J. Mohamad-saleh, "Hybrid bio-Inspired computational intelligence techniques for solving power system optimization problems : A comprehensive survey," Appl. Soft Comput. J., vol. 69, pp. 72-130, 2018.

[9] A. Y. Abdelaziz, Y. G. Hegazy, W. El-Khattam, and M. M. Othman, "Optimal allocation of stochastically dependent renewable energy based distributed generators in unbalanced distribution networks," Electr. Power Syst. Res., vol. 119, pp. 34-44, Feb. 2015.

[10] O. Olatunde and H. A. Rahman, "Allocation of distributed generation and capacitor banks in distribution system," Indones. J. Electr. Eng. Comput. Sci., vol. 13, no. 2, pp. 437-446, 2019.

[11] C. Yammani, S. Maheswarapu, and S. K. Matam, "A Multi-objective Shuffled Bat algorithm for optimal placement and sizing of multi distributed generations with different load models," Int. J. Electr. Power Energy Syst., vol. 79, pp. 120-131, 2016.

[12] K. Y. Liu, W. Sheng, Y. Liu, X. Meng, and Y. Liu, "Optimal sitting and sizing of DGs in distribution system considering time sequence characteristics of loads and DGs," Int. J. Electr. Power Energy Syst., vol. 69, pp. 430-440, 2015.

[13] A. M. El-Zonkoly, "Optimal placement of multi-distributed generation units including different load models using particle swarm optimisation,” IET Gener. Transm. Distrib., vol. 5, no. 7, p. 760, 2011.

[14] S. Dorahaki, "Optimal DG placement with the aim of profits maximization," Indones. J. Electr. Eng. Comput. Sci., vol. 1, no. 2, pp. 249-254, 2016.

[15] G. Chicco and P. Mancarella, "Distributed multi-generation: A comprehensive view," Renew. Sustain. Energy Rev., vol. 13, pp. 535-551, 2009.

[16] R. Viral and D. K. Khatod, "Optimal planning of distributed generation systems in distribution system: A review," 
Renew. Sustain. Energy Rev., vol. 16, no. 7, pp. 5146-5165, Sep. 2012.

[17] M. H. Hussain, I. Musirin, A. F. Abidin, and S. R. A. Rahim, "Modified swarm firefly algorithm method for directional overcurrent relay coordination problem," J. Theor. Appl. Inf. Technol., vol. 66, no. 3, pp. 741-755, 2014.

[18] S. R. A. Rahim et al., "Effect of Population Size for DG Installation using," 2013, no. June, pp. 746-751.

[19] W. L. Theo, J. S. Lim, W. S. Ho, H. Hashim, and C. T. Lee, "Review of distributed generation (DG) system planning and optimisation techniques: Comparison of numerical and mathematical modelling methods," Renew. Sustain. Energy Rev., vol. 67, pp. 531-573, 2017.

[20] N. A. Zambri, A. Mohamed, and M. Z. C. Wanik, "Performance comparison of neural networks for intelligent management of distributed generators in a distribution system," Int. J. Electr. Power Energy Syst., vol. 67, pp. 179-190, 2015.

[21] P. Prakash and D. K. Khatod, "Optimal sizing and siting techniques for distributed generation in distribution systems: A review,” Renew. Sustain. Energy Rev., vol. 57, pp. 111-130, 2016.

[22] K. Muthukumar and S. Jayalalitha, "Optimal placement and sizing of distributed generators and shunt capacitors for power loss minimization in radial distribution networks using hybrid heuristic search optimization technique," Int. J. Electr. Power Energy Syst., vol. 78, pp. 299-319, 2016.

[23] T. G. Manjunath and A. Kusagur, "Analysis of Different Meta Heuristics Method in Intelligent Fault Detection of Multilevel Inverter with Photovoltaic Power Generation Source,” Int. J. Power Electron. Drive Syst., vol. 9, no. 3, p. 1214, 2019.

[24] X. S. Yang, Nature-Inspired Optimization Algorithms. 2014.

[25] X. S. Yang, S. S. S. Hosseini, and A. H. Gandomi, "Firefly Algorithm for solving non-convex economic dispatch problems with valve loading effect," Appl. Soft Comput. J., vol. 12, no. 3, pp. 1180-1186, 2012.

[26] X.-S. Yang, "Swarm intelligence based algorithms: a critical analysis," Evol. Intell., vol. 7, no. 1, pp. 17-28, 2013.

[27] M. M. Aman, G. B. Jasmon, A. H. A. Bakar, and H. Mokhlis, "A new approach for optimum simultaneous multiDG distributed generation Units placement and sizing based on maximization of system loadability using HPSO (hybrid particle swarm optimization) algorithm,” Energy, Jan. 2014. 